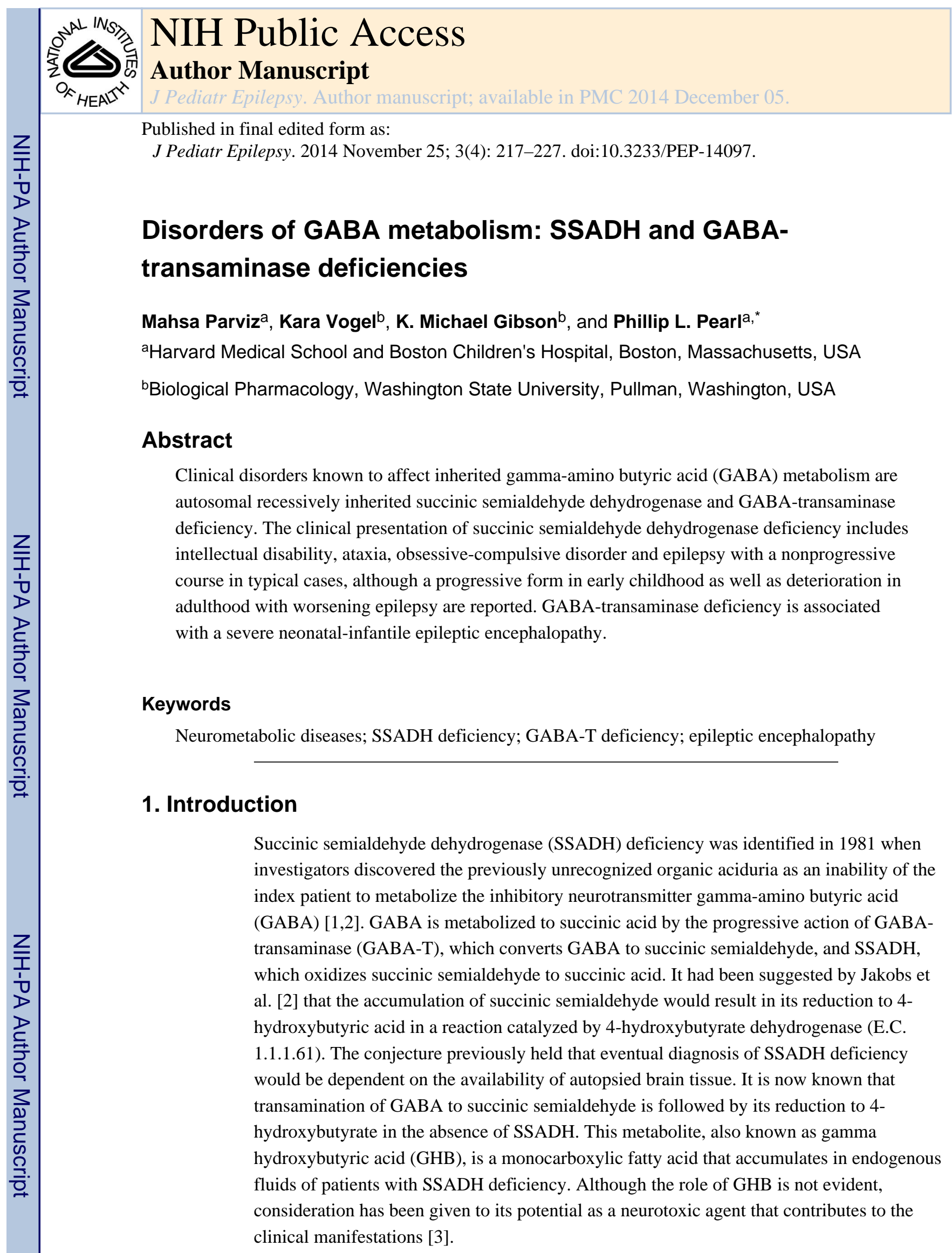

*Corresponding author: Dr. Phillip L. Pearl Department of Neurology, Harvard Medical School and Boston Children's Hospital Boston, MA, USA Tel.: +1 617355 2413; Fax: +1 6177300463 phillip.pearl@ childrens.harvard.edu.. 
Epstein-Barr virus-transformed lymphoblasts and identification of SSADH activity in peripheral leukocytes allowed Gibson et al. [4] to document SSADH deficiency in patients with 4-hydroxybutyric aciduria. Since then, the development of sensitive fluorometric and isotope dilution mass spectrometric methods have improved diagnostic accuracy [5]. Procedures in clinical identification have been developed which utilize a stable-isotope dilution liquid chromatography-tandem mass spectrometry method for detection of the unstable metabolite succinic semialdehyde in cerebrospinal fluid (CSF) and urine samples [6].

Consanguinity in many families and gene dosage effects in the parents of affected children have verified that SSADH deficiency is inherited in an autosomal recessive fashion. Advancements in genomics, proteomics and metabolomics have fostered the discovery of the complete SSADH amino acid sequence and its localization to chromosome 6p22 [7]. The genomic structure of the SSADH gene has been identified and the first inherited mutations responsible for SSADH deficiency were recognized by Chambliss et al. [8] in 1998.

\section{Metabolic pathways}

\subsection{The GABA metabolic pathway}

GABA was identified by Roberts and Frankel [9] in 1950 and later proposed to be an inhibitory neurotransmitter [10,11]. A ubiquitous thirty to forty percent of cerebral synapses utilize GABA to facilitate inhibition and it is the brain's major inhibitory neurotransmitter; only the excitatory neurotransmitter glutamate surpasses GABA concentrations in the central nervous system.

L-glutamate is converted into GABA via glutamate decarboxylase (GAD). The conversion of GABA to succinate is facilitated by the synchronous activity of SSADH and GABAtransaminase as GABA-T metabolizes GABA into succinic semialdehyde, which is rapidly metabolized to succinic acid and then enters the tricarboxylic acid cycle (Figure 1). Through the transamination of alpha-ketoglutarate, the closed loop of this process returns to glutamate and its conversion to GABA via GAD.

The transamination of GABA to succinic semialdehyde requires the presence of alphaketoglutarate to accept the amine group, a process that restores glutamate. The pool of neurotransmitters is continuously replenished as each mole of GABA converted to succinate yields one mole of glutamate [12].

In an ancillary loop known as the glutamine-glutamate shuttle, GABA is taken up by glial cells and, in the absence of GAD, is converted to glutamine via glutamine synthetase.

Glutamine is returned to the neuron and is converted back to glutamate via glutaminase, thus completing the loop and conserving the supply of GABA precursor.

Deficiencies in SSADH and GABA-T can severely disrupt the GABA metabolic pathway [13]. Homocarnosinosis has been proposed in a single case, an enzyme defect has not yet been conclusively proven, and this may represent carnosinase deficiency [14]. 


\subsection{SSADH deficiency}

SSADH deficiency is associated with early hypotonia and developmental delays, later expressive language impairment and obsessive-compulsive disorder, nonprogressive ataxia, hyporeflexia, and epilepsy (in about half of patients, sometimes severe). In the absence of SSADH, accumulation of GABA and its metabolite, GHB, indicate the diagnosis of SSADH deficiency. SSADH deficiency has been identified in hundreds of persons worldwide and homozygous or compound heterozygous mutations are found in the aldehyde dehydrogenase 5 family, member Al (ALDH5Al) gene in nearly all families sequenced. In at least $10 \%$ of cases, there is a more severe phenotype with developmental regression, myoclonic seizures, and extrapyramidal manifestations in the first year of life. There has also been increasing recognition of worsening epilepsy in adults.

\subsection{GABA-T deficiency}

GABA-T deficiency is associated with severe neonatal/early infantile epileptic encephalopathy and growth acceleration. The diagnosis may be detected using magnetic resonance spectroscopy with specialized editing for GABA or CSF analysis of GABA concentrations. GABA-T deficiency has been confirmed in two unrelated patients and an older sibling of one of these patients, who died at the age of $1 \mathrm{yr}$.

\subsection{Biochemical characteristics}

SSADH is a mitochondrial protein in the ALDH5Al, gene/locus MIM number 610045, MIM phenotype 271980. SSADH locates to the ALDH5Al gene at chromosome 6p22.3 and the product of SSADH is succinic acid. 4-aminobutyrate aminotransferase is a mitochondrial protein, OMIM 137150, correlating to OMIM phenotype 613163. GABA-T locates to the 4aminobutyrate aminotransferase (ABAT) gene at chromosome 16p13.2 and the product of GABA-T is succinic semialdehyde.

\section{Pathophysiology of SSADH and GABA-T deficiencies}

A murine model of SSADH deficiency was developed by Gibson et al. [15] via gene targeting. The ALDH5A1-/- mouse developed status epilepticus and died between postnatal days 20-26. This model has offered numerous opportunities for researchers to rethink the pathophysiology of inborn errors of metabolism in general and SSADH deficiency in particular [16]. In clinical cases of severe SSADH deficiency, seizures progress from absence to tonic-clonic to lethal status epilepticus, a sequence of progression also seen in ALDH5A1-/- mice [17-20]. Flumazenil-positron emission tomography and transcranial magnetic stimulation studies have shown evidence of GABA-dependent down-regulation of GABA-A and GABA-B receptors in animal studies as well as patients [21,22]. Because lethal status epilepticus is known to occur during the weaning period of newborn mice, and dam's milk has a high content of taurine, this sulfonated amino acid was studied and associated with extend lifespan in the affected mouse. Additional agents which increased lifespan were the GABA-T inhibitor vigabatrin, the GABA-B receptor antagonist 3aminopropyl (diethoxymethyl) phosphinic acid (CGP-35348), and the high-affinity GHB receptor antagonist NCS-382 [23,24], as well as a 4:1 ketogenic diet [25]. The GHB receptor antagonist 6,7,8,9-tetrahydro-5-hydroxy-5H-benzocyclohept-6-ylideneacetic acid 
(NCS-382) afforded maximal life extension for ALDH5A1-/- mice, providing evidence for a role of GHB in the pathophysiology. However, Mehta et al. [26] found no alterations in GHB receptor number, binding affinity and expression in ALDH5A1-/- brain sections. On the other hand, high-dose GHB (as found in the SSADH-deficient brain) activates a specific subset of GABA-B receptors [27].

Aside from accumulation of GABA and GHB, other metabolic disruptions that may contribute to the pathophysiology of SSADH deficiency include accumulation of succinic semialdehyde and 4,5-dihydroxyhexanoic acid, and the presence of disrupted glutamine homeostasis $[28,29]$. Enhanced oxidative stress has also been found in ALDH5A1-/- mice $[30,31]$. The mammalian target of rapamycin (mTor) receptor has been shown to be activated through increased GABA inhibited selected autophagic processes in yeast, including mitophagy and pexophagy [12]. These GABA-ergic effects were confirmed by significantly enhanced mitochondrial numbers in both the brain and liver of ALDH5A1-/mice, associated with increased biomarkers of oxidative stress.

The early lethality of the SSADH deficiency mouse model is useful in investigations of potential pharmacotherapies. Based on the above studies, rapamycin (sirolimus), an inactivator of mTor, may mitigate the effect of increased GABA on mTor and provide a new therapeutic consideration for SSADH deficiency and potentially GABA-T deficiency. Vigabatrin will reduce levels of GHB, as shown in CSF [28] of treated patients, but may exacerbate the effects of GABA in oxidative damage.

In GABA-T deficiency, the concentration of free GABA in CSF was 60 times higher in the index case than in controls [32] and 16 times higher in the second confirmed (unrelated) case [33]. The index case of GABA-T deficiency was identified through liver biopsy (15\% of normal GABA-T activity) [34]. The second confirmed case also had diminished GABA-T activity but not as severe as in the index case [33]. In central nervous system tissue, high levels of GABA and possibly beta-alanine may be causative of the encephalopathy of GABA-T deficiency. Unlike in the case of SSADH deficiency, elevated homocarnosine is not likely the cause of the neurological picture in GABA-T deficiency, as a clinically normal adult with much higher CSF homocarnosine levels than seen in the index case has been reported [35]. The finding of growth acceleration in GABA-T deficiency may be related to a stimulating effect of GABA on the release of growth hormone [36].

\section{Clinical characteristics}

\subsection{SSADH deficiency}

SSADH deficiency is an autosomal recessive disorder with an onset of symptoms at a mean age of $11 \mathrm{mo}$ (range 0-44 mo) [37]. A slowly progressive or static encephalopathy results with some patients showing regression, although early-onset cases may result in more severe sequelae, with extrapyramidal signs and death in infancy [38]. Typical signs are developmental delay, hypotonia, hyporeflexia, and ataxia [39]. Moderate to severe cognitive delays are most prominent as language deficits [39]. Epilepsy arises in half of patients, usually as generalized tonic-clonic seizures although sometimes absence and myoclonic seizures occur [40]. Electroencephalography (EEG) shows background slowing and spike- 
and-wave discharges, usually generalized. Basal ganglia signs may be present, including choreoathetosis, dystonia, and myoclonus. Neuropsychiatric problems are often disabling and affect more than two-thirds of patients. These include attention deficit hyperactivity disorder and aggression in early childhood, and anxiety and obsessive-compulsive disorder in adolescence and adulthood [41,42]. Other behavioral signs include self-injurious behaviors, autistic behaviors, and hallucinations. Sleep disturbances are common, including difficulties with initiating or maintaining sleep [43,44]. Polysomnography shows prolonged latency to stage rapid eye movement (REM), decreased percentage stage REM sleep, and decreased mean sleep latency on diurnal multiple sleep latency testing, consistent with excessive daytime somnolence associated with decreased REM sleep [45].

Magnetic resonance imaging (MRI) of the brain shows increased T2 and fluid attenuated inversion recovery hyperintense signal, usually bilaterally and symmetrically, in the globus pallidi, cerebellar dentate nuclei, subthalamic nuclei, subcortical white matter, and brain stem. Cerebral and cerebellar atrophy have also been noted. Magnetic resonance spectroscopy shows an enlarged glx peak consistent with increased endogenous GABA in brain parenchyma.

The following tables summarize data on common clinical features, seizure categories, and EEG information obtained from $\mathrm{n}=111$ patients enrolled in a clinical registry. Developmental delay is the most prevalent presentation. Common features include intellectual disability, behavior problems, and hypotonia (Table 1). We report on a patient cohort consisting of $43 \%$ males and a mean age of $16 \mathrm{yr}$ (range 0.3-63 yr). The mean age when symptoms first appeared was 11 mo (range 0-44 mo) and the mean age at diagnosis was $4.34 \mathrm{yr}$, although some individuals were not diagnosed until $25 \mathrm{yr}$ of age or later. More than half of patients exhibit some form of seizure activity; a majority of whom develop epilepsy, usually with generalized tonic-clonic and atypical absence seizures (Table 2). Many patients display sporadic but recurrent episodes of generalized convulsive status epilepticus and as such, the epilepsy may be difficult to control. EEG findings revealed a near-even distribution of patients presenting with normal to abnormal EEG outcomes which include background slowing, epileptiform abnormalities (most frequently generalized but sometimes multifocal), and occasionally photosensitivity and electrographic status epilepticus of sleep (Table 3).

\subsection{GABA-T deficiency}

Deficiency in GABA-transaminase has been detected in one index sibship and one additional patient [46]. The index case was a female in whom the disorder was confirmed enzymatically; an older brother died at $1 \mathrm{yr}$ of age after displaying similar symptoms, but the disorder was not confirmed at that time. The third patient was a confirmed case from an unrelated family [33]. Rarity of the disorder may be due to in utero death or the infrequency of recessive alleles, but diagnosis is likely impeded by the general lack of availability of CSF testing for GABA concentrations. The phenotype appears much more severe than that associated with SSADH, perhaps correlated with the higher intracerebral accumulation of GABA. An "induced" model of GABA-T deficiency exists in the pharmacotherapy of infantile spasms using vigabatrin (gamma-vinyl-GABA) [47]. 
The index family with this disorder exhibited neonatal seizures, lethargy, hypotonia, hyperreflexia, poor feeding, severely impaired psychomotor development, and a highpitched cry $[13,32,36,48]$. Circumference of the head grew rapidly in the index's sibling, up to the 97th percentile, while the index patient's head circumference was at the 75th percentile and her linear growth over the 97th percentile at the age of 2 yr. Her visual, auditory and somatosensory evoked potentials were absent at that age.

Computed tomography of the brain in both patients from the index family showed severe ventricular enlargement and increased cisternal and sulcal spaces. Neuropathologic examination of the index patient's sibling revealed a spongiform quality of the white matter in cerebral hemispheres, cerebellum, and brainstem; there was poor or absent myelination in the white matter of the gyri [34].

In the second confirmed (unrelated) case of GABA-T deficiency, symptoms manifested at 7 mo of age with hypotonia, developmental delay, hyperreflexia, and myoclonias. Several anti-epileptics were unsuccessful at controlling the seizures, and at age 8 mo EEG showed diffuse spike-and-wave activity with background suppression. Computed tomography was normal. Brain MRI showed no structural abnormalities but mild delay in myelination. Diffusion-weighted imaging showed increased signal intensity in the internal and external capsules and the subcortical white matter; apparent diffusion capacity was restricted [33].

\section{Diagnosis}

\subsection{SSADH deficiency}

A diagnosis of SSADH deficiency should be considered in cases of a slowly progressive or static encephalopathy with late-infantile to early-childhood onset and the aforementioned primary clinical features, particularly expressive language delays with hyporeflexia, ataxia, and fine motor incoordination.

The most reliable laboratory test findings are on urine organic acid analysis, specifically gas chromatography mass spectrometry. The finding of GHB on urine organic acid analysis (100-1200 $\mathrm{mmol} / \mathrm{mol}$ creatine [normal, 0-7 $\mathrm{mmol} / \mathrm{mol}$ creatinine]) suggests SSADH deficiency, and the combination of this finding with 4,5-dihydroxyhexanoic acid (free acid and internal threo- and erythro- lactones) appears pathognomonic for SSADH deficiency. 4,5-dihydroxyhexanoic acid appears to derive from condensation of accumulated succinic semialdehyde with a 2-carbon moiety derived from the pyruvate cycle [49,50]. Other metabolites in urine associated with GHB include D-2-hydroxyglutarate (deriving from the action of D-2-hydroxyglutarate transhydrogenase, an NAD+-independent enzyme which utilizes GHB), as well as putative metabolites of GHB such as 3-oxo-4-hydroxybutyric acid and the tetronic acid 3,4-dihydroxybutyrate [50]. Urine organic acid analysis should be considered in patients whose developmental delays or neuropsychiatric disturbances are of unknown etiology.

Plasma findings in SSADH deficiency include 4-hydroxybutyric acid (35-600 micromol/L [normal, 0-3 micromol/L]) and low SSADH enzyme activity in lymphocytes (less than 5\% compared with controls). Findings in CSF include 4-hydroxybutyric acid (100-850 
micromol/L [normal, 0-2 micromol/L]), elevated GABA with neurotransmitter measurement, and potential elevation of homocarnosine and carnosine (beta-alanine and Lhistidine dipeptide).

Clinical molecular genetic testing of the ALDH5A1 gene can confirm the diagnosis. In a report of 54 families, sequence analysis identified variants in 97\% [51]. A novel 34-bp insertion in exon 10, identified through deletion/duplication analysis, resulted in a frameshift mutation in which a truncated SSADH protein lacked 50 amino acids in the C-terminus [52]. One-third of patients with SSADH deficiency have normal EEGs. As for the other twothirds, EEG shows background slowing and spike discharges, usually generalized [39]. A report of two family members heterozygous for SSADH deficiency included EEG findings of generalized spike-wave discharges, photosensitivity, and absence and myoclonic seizures [53]. Electrographic status epilepticus of slow wave sleep occurs rarely, as does photosensitivity.

Symmetrically increased T2-weighted signal on cranial MRI appears in a pallidodentatoluysian pattern involving the bilateral globus pallidi, cerebellar dentate nuclei, and subthalamic nuclei [22], but asymmetric or partial involvement can also occur. Other reports locate T2-hyperintensities in subcortical white matter and the brain stem, as well as findings of cerebral atrophy, cerebellar atrophy, and delayed myelination [54,55].

\subsection{GABA-T deficiency}

Diagnosis of GABA-T deficiency relies on measurement of CSF amino acid concentrations. One challenge in the diagnosis may be that the invasiveness of the necessary testing leads to attenuated diagnostic yield. The major diagnostic sign is elevated free GABA in CSF; CSF beta-alanine is also elevated. There is no CSF elevation of gamma-hydroxybutyric acid. Serum may show elevated GABA and beta-alanine, and possibly elevated carnosine. However, the sibling of the index case had normal plasma amino acid concentrations. Proton magnetic resonance spectroscopy has detected a significant increase of in vivo GABA concentration in the basal ganglia [33]. Pharmacologic administration of vigabatrin, which reproduces the biochemical profile of GABA-T deficiency, produces MRI signal abnormalities characterized principally by $\mathrm{T} 2$-weighted hyperintensity maximally involving the basal ganglia, thalami, and brainstem [56,57].

In the index patient, an A-to-G transition at nucleotide 754 of the human GABA-T gene was identified in lymphoblast cDNA (c.754A $>$ G), resulting in substitution of an invariant arginine at amino acid 220 by lysine (p.Arg220Lys). This mutation results in destabilization of the binding of pyridoxal-5'-phosphate to GABA-transaminase, which is required for the transamination of GABA to succinic semialdehyde. The second allele in this patient was later identified as c.1433T $>C$, causing the substitution p.Leu478Pro [46,58].

The unrelated patient was also a compound heterozygote, with a missense mutation c. $275 \mathrm{G}>\mathrm{A}$ and a deletion of nucleotides 199 to 316 of the GABA-transaminase coding region [32]. Metabolic acidosis is absent in both GABA-T and SSADH deficiencies. 


\subsection{Differential diagnosis for SSADH}

The differential diagnosis for SSADH deficiency includes homocarnosinosis, but an enzyme defect has not yet been conclusively proven in the single reported case [14] and it may instead represent a variant form of carnosinase deficiency. Similar bilateral signal abnormalities in the globus pallidi on MRI may be observed in other organic acidurias, such as methylmalonic aciduria, mitochondrial disorders, pantothenate kinase-associate neurodegeneration, and neuroferritinopathy. Leigh syndrome, kernicterus, liver failure, and neonatal hypoxic-ischemic encephalopathy show similar evidence of subthalamic nucleus involvement on MRI [59]. However, metabolic stroke, megalencephaly, episodic hypoglycemia, hyperammonemia, and acidosis are not usually associated with SSADH deficiency, despite their association with other metabolic encephalopathies and some other organic acidurias [40].

The presence of GHB in urine, the key laboratory screen in SSADH deficiency, may in fact be due to other disorders and possibly due to the use of GHB as a drug of abuse and in other settings [60]. False elevations of GHB have been noted in individuals from whom urine was obtained using Coloplast SpeediCath catheters, which have been found to have high GHB concentrations [61]. GHB is also used as pharmacotherapy for narcolepsy with cataplexy. Nonetheless, if the finding is repeated on urine organic acid analyses and associated with suggestive clinical signs and symptoms, then molecular diagnostic studies are warranted to corroborate the diagnosis.

\subsection{Differential diagnosis for GABA-T deficiency}

The differential diagnosis for GABA-T deficiency should take into account a reported patient in whom increased CSF and plasma GABA levels were associated with hyper-betaalaninemia [60]; however, the CSF beta-alanine concentrations in the latter patient were significantly higher than those found in the index patient with GABA-T deficiency. Other factors in the clinical and metabolic presentations differed as well, but the possibility remains that GABA-T deficiency and hyper-beta-alaninemia are variants of one another.

Although a number of other disorders share certain clinical features with GABA-T deficiency (e.g. globoid cell leukodystrophy, cerebral gigantism, Pelizaeus-Merzbacher disease), the significant elevations of GABA and beta-alanine in CSF remain the key findings that distinguish GABA-T deficiency [61].

\subsection{Diagnostic issues}

If a disease-causing mutation of either of these disorders has been identified in a family, prenatal diagnosis is possible through amniocentesis (measurement in amniotic fluid of GHB for SSADH deficiency, or potentially of GABA and beta-alanine for GABA-T deficiency) or chorionic villus tissue and cultured amniocytes (measurement of SSADH or potentially GABA-T enzyme activity).

Forni et al. [62] demonstrated feasibility of dried blood spot testing for GHB within newborn metabolic screenings for earlier diagnosis of SSADH deficiency. However, late 
diagnosis remains a concern, as the non-specific clinical phenotype has led to adult patients being undiagnosed for decades [63].

\section{Management}

\subsection{Evaluations}

The following evaluations should be performed after diagnosis in order to provide baseline data as well as to guide the selection and efficacy of treatment options:

a. Regular neurological and developmental assessments are recommended to determine the nature and extent of the motor and cognitive delays, and to monitor for changes that might indicate treatment effectiveness or worsening of the underlying etiology.

b. Neuroimaging (MRI). Although the encephalopathy is generally static, the possibility of slow progression is associated with these disorders, thus warranting baseline brain imaging and repeat imaging in cases of worsening deficits.

c. EEG. The majority of patients with SSADH deficiency, and all patients with GABA-T deficiency, experience seizure activity, which can be severe. Seizures may develop after the onset of other symptoms. In the index case of GABA-T deficiency, EEG was normal at 2 wk of age but by the age of 2 yr showed generalized epileptiform paroxysms.

d. Genetic counseling is recommended given autosomal recessive inheritance, and to offer the potential for prenatal diagnosis.

\subsection{SSADH management}

Adults with SSADH deficiency will require some degree of supervision, and thus long-term management focuses on assistance with activities of daily living so that patients may live as independently as possible. A database of 112 patients includes 41 individuals age $18 \mathrm{yr}$ and older. Of these, 27 (66\%) have epilepsy, typically with generalized convulsive and nonconvulsive seizures. Sudden unexpected death has been reported [64], as well as progressive worsening with accelerating convulsive seizures and dementia up to age $63 \mathrm{yr}$ [63]. Neuropsychiatric complications and sleep disturbances are commonly noted. Anxiety and obsessive-compulsive disorder appear especially prominent and at times disabling in adolescence and adulthood.

\subsection{GABA-T deficiency management}

In GABA-T deficiency, the index family patients died at 1 and $2 \mathrm{yr}$ of age; the unrelated patient was alive at $28 \mathrm{mo}$ of age. Most therapeutic interventions have aimed to provide symptomatic treatment of motor difficulties and seizures. The inborn error in this disorder may be lethal in utero or before metabolic diagnosis can be made in the neonatal period.

\section{Treatment}

At this time, no effective pharmacological strategies exist to address the underlying deficiencies. The major goal of treatment is therefore phenotypical management of the most 
disabling symptoms, i.e. seizures and neurobehavioral disturbances, especially obsessivecompulsive and anxiety disorders in SSADH deficiency. Pyridoxine (up to $3 \times 1 \mathrm{~g} / \mathrm{d}$ ) and picrotoxin (up to $0.12 \mathrm{mg} / \mathrm{kg}$ per day) have been attempted in the index case of GABA-T deficiency without evidence of improvement.

The epilepsy of SSADH deficiency is usually characterized by generalized epileptiform EEG discharges which guides antiepileptic drug therapy to a limited extent. Patients have responded to lamotrigine and carbamazepine, despite the voltage-sensitive sodium channel blockage effects occasionally associated with exacerbation of generalized seizures. Vigabatrin, an irreversible inhibitor of GABA-transaminase, has been prescribed for seizure control in SSADH [64]; however, the results are inconsistent [65]. In one uncontrolled, nonblinded trial of vigabatrin, plasma GHB concentrations decreased in two pediatric patients and verbal communication improved in one [66]. In a similar trial, slow clinical improvement, which was not inconsistent with the natural history of SSADH deficiency, was seen in one child on vigabatrin [67]. Vigabatrin led to seizures in one individual for whom lamotrigine was successful [68]. This inconsistency may be due to a limited effect of vigabatrin on peripheral GABA-T, with the resulting peripheral GHB resupplying the brain and decreasing the drug's effectiveness [69], in addition to increased GABA levels secondary to vigabatrin effect [70]. Improved understanding of the long-term effects of vigabatrin intervention in patients with infantile spasms may provide insights into the defects of GABA metabolism that are associated with increased central nervous system GABA.

Although magnesium valproate treatment controlled refractory epilepsy in a single SSADHdeficient patient, who then remained seizure-free for a year, showing improved behavior and EEG findings [71], valproate may inhibit residual SSADH enzyme activity and therefore is generally avoided, at least as a first-line agent [72].

Following an initial anecdotal report of improvement in development with taurine, an open label trial did not result in significant improvement in adaptive behavioral domains [73]. Methylphenidate, risperidone, fluoxetine, thioridazine, and benzodiazepines when administered at standard dosages have demonstrated to be effective therapies for inattention, aggressiveness, and anxiety [74].

Nonpharmacologic interventions include physical and occupational therapies to assist patients with gaining and maintaining strength, endurance, balance, fine motor skills, feeding, and sensory integration. Speech and communication therapy is also advised to improve articulation and provide alternative communication modalities.

\section{Future directions for biomarkers, therapy, and clinical trials}

New insights into GABA-related biology have burgeoned from studies of SSADH and reports of GABA-T deficiencies, expanding our understanding of GABA past its role as an inhibitory neurotransmitter. In addition, these two disorders provide opportunities to reform fundamental questions regarding epileptic mechanisms [12]. The paucity of GABA-T deficient patients suggests we are still defining the GABA-T deficient phenotype, but existing reports beget a foundation for further investigations. 
The murine knockout model of SSADH deficiency has provided valuable information on pathomechanisms associated with human SSADH deficiency and the neurophysiological consequences of a hyperGABA-ergic state. Preclinical pharmacotherapeutic studies in this model have evolved into two ongoing-clinical trials [73], and planning for additional trials is in progress.

Positron emission tomography, showing decreased flumazenil binding indicative of GABAA receptor activity [75], and transcranial magnetic stimulation, showing significant shortening of the cortical silent period and reduced long interval intracortical inhibition indicative of decreased GABA-B neurotransmission [37], have been used to provide biomarkers for clinical trials.

Several potential therapeutics are currently being investigated for SSADH deficiency. Taurine is being examined in a clinical trial, as is the GABA-B receptor antagonist, SGS-742 (www.clinicaltrials.gov; NCT01608178; NCT02019667). Targeted antioxidants, NCS-382 (or similar GHB receptor antagonists), and inducers of autophagy are also being considered to improve redox imbalances in patients, but more data in this area is necessary prior to the initiation of clinical trials $[12,20]$.

In these disorders, long-term management must contend with diverse symptoms and various underlying mechanisms. For each of the manifestations, the extent of improvement that is possible may be miniscule, however combination therapies best address the complex clinical manifestation and offer maximum benefits to patients. The therapeutic relevance of prophylactic antioxidant therapy in SSADH deficiency is highlighted by the documented susceptibility of SSADH to disruption in the intracellular redox balance, as shown by Kim et al. [76] in the crystal structure of bacterial and human SSADH [16].

\section{References}

1. Pearl PL, Novotny EJ, Acosta MT, Jakobs C, Gibson KM. Succinic semialdehyde dehydrogenase deficiency in children and adults. Ann Neurol. 2003b; 54(Suppl 6):S73-80. [PubMed: 12891657]

2. Jakobs C, Bojasch M, Monch E, Rating D, Siemes H, Hanefeld F. Urinary excretion of gammahydroxybutyric acid in a patient with neurological abnormalities. The probability of a new inborn error of metabolism. Clin Chim Acta. 1981; 111(2-3):169-78. [PubMed: 7226548]

3. Pearl PL, Gibson KM, Acosta MT, Vezina LG, Theodore WH, Rogawski MA, et al. Clinical spectrum of succinic semialdehyde dehydrogenase deficiency. Neurology. 2003a; 60(9):1413-7. [PubMed: 12743223]

4. Gibson KM, Sweetman L, Nyhan WL, Jakobs C, Rating D, Siemes H, et al. Succinic semialdehyde dehydrogenase deficiency: an inborn error of gamma-aminobutyric acid metabolism. Clin Chim Acta. 1983; 133(1):33-42. [PubMed: 6627675]

5. Gibson KM, Aramaki S, Sweetman L, Nyhan WL, DeVivo DC, Hodson AK, et al. Stable isotope dilution analysis of 4-hydroxybutyric acid: an accurate method for quantification in physiological fluids and the prenatal diagnosis of 4-hydroxybutyric aciduria. Biomed Environ Mass Spectrom. 1990b; 19(2):89-93. [PubMed: 2407302]

6. Struys EA, Jansen EE, Gibson KM, Jakobs C. Determination of the GABA analogue succinic semialdehyde in urine and cerebrospinal fluid by dinitrophenylhydrazine derivatization and liquid chromatography-tandem mass spectrometry: application to SSADH deficiency. J Inherit Metab Dis. 2005; 28(6):913-20. [PubMed: 16435183] 
7. Trettel F, Malaspina P, Jodice C, Novelletto A, Slaughter CA, Caudle DL, et al. Human succinic semialdehyde dehydrogenase. Molecular cloning and chromosomal localization. Adv Exp Med Biol. 1997; 414:253-60. [PubMed: 9059628]

8. Chambliss KL, Hinson DD, Trettel F, Malaspina P, Novelletto A, Jakobs C, et al. Two exonskipping mutations as the molecular basis of succinic semialdehyde dehydrogenase deficiency (4hydroxybutyric aciduria). Am J Hum Genet. 1998; 63(2):399-408. [PubMed: 9683595]

9. Roberts E, Frankel S. gamma-Aminobutyric acid in brain: its formation from glutamic acid. J Biol Chem. 1950; 187(1):55-63. [PubMed: 14794689]

10. Curtis DR, Watkins JC. The excitation and depression of spinal neurones by structurally related amino acids. J Neurochem. 1960; 6:117-41. [PubMed: 13718948]

11. Krnjevic K, Schwartz S. The action of gamma-aminobutyric acid on cortical neurones. Exp Brain Res. 1967; 3(4):320-36. [PubMed: 6031164]

12. Lakhani R, Vogel KR, Till A, Liu J, Burnett SF, Gibson KM, et al. Defects in GABA metabolism affect selective autophagy pathways and are alleviated by mTOR inhibition. EMBO Mol Med. 2014; 6(4):551-66. [PubMed: 24578415]

13. Gibson KM, Nyhan WL, Jaeken J. Inborn errors of GABA metabolism. Bioessays. 1986; 4(1):247. [PubMed: 3790108]

14. Gibson, KM.; Jakobs, C. Disorders of beta- and alpha-amino acids in free and peptide-linked forms.. In: Scriver, CR.; Beaudet, AL.; Sly, WS.; Valle, D.; Childs, B.; Kinzler, KW.; Vogelstein, B., editors. The metabolic and molecular bases of inherited disease. 8th ed.. McGraw-Hill; New York: 2001. p. 2079-105.

15. Gibson KM, Jakobs C, Pearl PL, Snead OC. Murine succinate semialdehyde dehydrogenase (SSADH) deficiency, a heritable disorder of GABA metabolism with epileptic phenotype. IUBMB Life. 2005; 57(9):639-44. [PubMed: 16203683]

16. Kim KJ, Pearl PL, Jensen K, Snead OC, Malaspina P, Jakobs C, et al. Succinic semialdehyde dehydrogenase: biochemical-molecular-clinical disease mechanisms, redox regulation, and functional significance. Antioxid Redox Signal. 2011; 15(3):691-718. [PubMed: 20973619]

17. Cortez MA, Wu Y, Gibson KM, Snead OC 3rd. Absence seizures in succinic semialdehyde dehydrogenase deficient mice: a model of juvenile absence epilepsy. Pharmacol Biochem Behav. 2004; 79(3):547-53. [PubMed: 15582027]

18. Buzzi A, Wu Y, Frantseva MV, Perez Velazquez JL, Cortez MA, Liu CC, et al. Succinic semialdehyde dehydrogenase deficiency: GABAB receptor-mediated function. Brain Res. 2006; 1090(1):15-22. [PubMed: 16647690]

19. Wu Y, Buzzi A, Frantseva M, Velazquez JP, Cortez M, Liu C, et al. Status epilepticus in mice deficient for succinate semialdehyde dehydrogenase: GABAA receptor-mediated mechanisms. Ann Neurol. 2006; 59(1):42-52. [PubMed: 16240371]

20. Vogel KR, Pearl PL, Theodore WH, McCarter RC, Jakobs C, Gibson KM. Thirty years beyond discovery--clinical trials in succinic semialdehyde dehydrogenase deficiency, a disorder of GABA metabolism. J Inherit Metab Dis. 2013; 36(3):401-10. [PubMed: 22739941]

21. Reis J, Cohen LG, Pearl PL, Fritsch B, Jung NH, Dustin I, et al. GABAB-ergic motor cortex dysfunction in SSADH deficiency. Neurology. 2012; 79(1):47-54. [PubMed: 22722631]

22. Pearl PL, Gibson KM, Quezado Z, Dustin I, Taylor J, Trzcinski S, et al. Decreased GABA-A binding on FMZ-PET in succinic semialdehyde dehydrogenase deficiency. Neurology. 2009; 73(6):423-9. [PubMed: 19667317]

23. Hogema BM, Akaboshi S, Taylor M, Salomons GS, Jakobs C, Schutgens RB, et al. Prenatal diagnosis of succinic semialdehyde dehydrogenase deficiency: increased accuracy employing DNA, enzyme, and metabolite analyses. Mol Genet Metab. 2001; 72(3):218-22. [PubMed: 11243727]

24. Gupta M, Greven R, Jansen EE, Jakobs C, Hogema BM, Froestl W, et al. Therapeutic intervention in mice deficient for succinate semialdehyde dehydrogenase (gamma-hydroxybutyric aciduria). $\mathrm{J}$ Pharmacol Exp Ther. 2002; 302(1):180-7. [PubMed: 12065715]

25. Nylen K, Velazquez JL, Likhodii SS, Cortez MA, Shen L, Leshchenko Y, et al. A ketogenic diet rescues the murine succinic semialdehyde dehydrogenase deficient phenotype. Exp Neurol. 2008; 210(2):449-57. [PubMed: 18199435] 
26. Mehta AK, Gould GG, Gupta M, Carter LP, Gibson KM, Ticku MK. Succinate semialdehyde dehydrogenase deficiency does not down-regulate gamma-hydroxybutyric acid binding sites in the mouse brain. Mol Genet Metab. 2006; 88(1):86-9. [PubMed: 16406647]

27. Bay T, Eghorn LF, Klein AB, Wellendorph P. GHB receptor targets in the CNS: focus on highaffinity binding sites. Biochem Pharmacol. 2014; 87(2):220-8. [PubMed: 24269284]

28. Gibson KM. Gamma-hydroxybutyric aciduria: a biochemist's education from a heritable disorder of GABA metabolism. J Inherit Metab Dis. 2005; 28(3):247-65. [PubMed: 15868461]

29. Chowdhury GM, Gupta M, Gibson KM, Patel AB, Behar KL. Altered cerebral glucose and acetate metabolism in succinic semialdehyde dehydrogenase-deficient mice: evidence for glial dysfunction and reduced glutamate/glutamine cycling. J Neurochem. 2007; 103(5):2077-91. [PubMed: 17854388]

30. Sgaravatti AM, Sgarbi MB, Testa CG, Durigon K, Pederzolli CD, Prestes CC, et al. Gammahydroxybutyric acid induces oxidative stress in cerebral cortex of young rats. Neurochem Int. 2007; 50(3):564-70. [PubMed: 17197055]

31. Latini A, Scussiato K, Leipnitz G, Gibson KM, Wajner M. Evidence for oxidative stress in tissues derived from succinate semialdehyde dehydrogenase-deficient mice. J Inherit Metab Dis. 2007; 30(5):800-10. [PubMed: 17885820]

32. Jakobs C, Jaeken J, Gibson KM. Inherited disorders of GABA metabolism. J Inherit Metab Dis. 1993; 16(4):704-15. [PubMed: 8412016]

33. Tsuji M, Aida N, Obata T, Tomiyasu M, Furuya N, Kurosawa K, et al. A new case of GABA transaminase deficiency facilitated by proton MR spectroscopy. J Inherit Metab Dis. 2010; 33(1): 85-90. [PubMed: 20052547]

34. Jaeken J, Casaer P, de Cock P, Corbeel L, Eeckels R, Eggermont E, et al. Gamma-aminobutyric acid-transaminase deficiency: a newly recognized inborn error of neurotransmitter metabolism. Neuropediatrics. 1984; 15(3):165-9. [PubMed: 6148708]

35. Sjaastad O, Berstad J, Gjesdahl P, Gjessing L. Homocarnosinosis. 2. A familial metabolic disorder associated with spastic paraplegia, progressive mental deficiency, and retinal pigmentation. Acta Neurol Scand. 1976; 53(4):275-90. [PubMed: 1266573]

36. Jaeken J, Casaer P, Haegele KD, Schechter PJ. Review: Normal and abnormal central nervous system GABA metabolism in childhood. J Inherit Metab Dis. 1990; 13(6):793-801. [PubMed: 2079831]

37. Pearl PL, Gibson KM, Acosta MT, Vezina LG, Theodore WH, Rogawski MA, et al. Clinical spectrum of succinic semialdehyde dehydrogenase deficiency. Neurology. 2003; 60(9):1413-7. [PubMed: 12743223]

38. Pearl PL, Gibson KM, Cortez MA, Wu Y, Carter Snead O 3rd, Knerr I, et al. Succinic semialdehyde dehydrogenase deficiency: lessons from mice and men. J Inherit Metab Dis. 2009; 32(3):343-52. [PubMed: 19172412]

39. Pearl, PL.; Acosta, MT.; Wallis, DD., et al. Dyskinetic features of succinate semialdehyde dehydrogenase deficiency, a GABA degradative defect.. In: Fernandez-Alvarez, E.;

Arzimanoglou, A.; Tolosa, E., editors. Paediatric movement disorders: Progress in understanding. John Libbey Eurotext; Surrey UK: 2005. p. 203-12.

40. Pearl PL, Capp PK, Novotny EJ, Gibson KM. Inherited disorders of neurotransmitters in children and adults. Clin Biochem. 2005; 38(12):1051-8. [PubMed: 16298354]

41. Pearl PL, Gibson KM. Clinical aspects of the disorders of GABA metabolism in children. Curr Opin Neurol. 2004; 17(2):107-13. [PubMed: 15021235]

42. Knerr I, Gibson KM, Jakobs C, Pearl PL. Neuropsychiatric morbidity in adolescent and adult succinic semialdehyde dehydrogenase deficiency patients. CNS Spectr. 2008; 13(7):598-605. [PubMed: 18622364]

43. Philippe A, Deron J, Genevieve D, de Lonlay P, Gibson KM, Rabier D, et al. Neurodevelopmental pattern of succinic semialdehyde dehydrogenase deficiency (gamma-hydroxybutyric aciduria). Dev Med Child Neurol. 2004; 46(8):564-8. [PubMed: 15287248]

44. Arnulf I, Konofal E, Gibson KM, Rabier D, Beauvais P, Derenne JP, et al. Effect of genetically caused excess of brain gamma-hydroxybutyric acid and GABA on sleep. Sleep. 2005; 28(4):41824. [PubMed: 16171286] 
45. Pearl PL, Shamim S, Theodore WH, Gibson KM, Forester K, Combs SE, et al. Polysomnographic abnormalities in succinic semialdehyde dehydrogenase (SSADH) deficiency. Sleep. 2009; 32(12): 1645-8. [PubMed: 20041601]

46. Medina-Kauwe LK, Tobin AJ, De Meirleir L, Jaeken J, Jakobs C, Nyhan WL, et al. 4Aminobutyrate aminotransferase (GABA-transaminase) deficiency. J Inherit Metab Dis. 1999; 22(4):414-27. [PubMed: 10407778]

47. Gaily E. Vigabatrin monotherapy for infantile spasms. Expert Rev Neurother. 2012; 12(3):275-86. [PubMed: 22364326]

48. Jaeken J. Metabolic diseases: a challenge for pediatrics. Verh K Acad Geneeskd Belg. 1990; 52(3): 293-7. in Dutch. [PubMed: 2220032]

49. Brown GK, Cromby CH, Manning NJ, Pollitt RJ. Urinary organic acids in succinic semialdehyde dehydrogenase deficiency: evidence of alpha-oxidation of 4-hydroxybutyric acid, interaction of succinic semialdehyde with pyruvate dehydrogenase and possible secondary inhibition of mitochondrial beta-oxidation. J Inherit Metab Dis. 1987; 10(4):367-75. [PubMed: 3126356]

50. Janssen AJ, Schuelke M, Smeitink JA, Trijbels FJ, Sengers RC, Lucke B, et al. Muscle 3243A-->G mutation load and capacity of the mitochondrial energy-generating system. Ann Neurol. 2008; 63(4):473-81. [PubMed: 18306232]

51. Akaboshi S, Hogema BM, Novelletto A, Malaspina P, Salomons GS, Maropoulos GD, et al. Mutational spectrum of the succinate semialdehyde dehydrogenase (ALDH5A1) gene and functional analysis of 27 novel disease-causing mutations in patients with SSADH deficiency. Hum Mutat. 2003; 22(6):442-50. [PubMed: 14635103]

52. Kwok JS, Yuen CL, Law LK, Tang NL, Cherk SW, Yuen YP. A novel ALDH5A1 mutation in a patient with succinic semialdehyde dehydrogenase deficiency. Pathology. 2012; 44(3):280-2. [PubMed: 22437753]

53. Dervent A, Gibson KM, Pearl PL, Salomons GS, Jakobs C, Yalcinkaya C. Photosensitive absence epilepsy with myoclonias and heterozygosity for succinic semialdehyde dehydrogenase (SSADH) deficiency. Clin Neurophysiol. 2004; 115(6):1417-22. [PubMed: 15134710]

54. Yalcinkaya C, Gibson KM, Gunduz E, Kocer N, Ficicioglu C, Kucukercan I. MRI findings in succinic semialdehyde dehydrogenase deficiency. Neuropediatrics. 2000; 31(1):45-6. [PubMed: 10774997]

55. Ziyeh S, Berlis A, Korinthenberg R, Spreer J, Schumacher M. Selective involvement of the globus pallidus and dentate nucleus in succinic semialdehyde dehydrogenase deficiency. Pediatr Radiol. 2002; 32(8):598-600. [PubMed: 12136353]

56. Pearl PL, Vezina LG, Saneto RP, McCarter R, Molloy-Wells E, Heffron A, et al. Cerebral MRI abnormalities associated with vigabatrin therapy. Epilepsia. 2009; 50(2):184-94. [PubMed: 18783433]

57. Wheless JW, Carmant L, Bebin M, Conry JA, Chiron C, Elterman RD, et al. Magnetic resonance imaging abnormalities associated with vigabatrin in patients with epilepsy. Epilepsia. 2009; 50(2): 195-205. [PubMed: 19054414]

58. Medina-Kauwe LK, Nyhan WL, Gibson KM, Tobin AJ. Identification of a familial mutation associated with GABA-transaminase deficiency disease. Neurobiol Dis. 1998; 5(2):89-96. [PubMed: 9746906]

59. Bosemani T, Anghelescu C, Boltshauser E, Hoon AH Jr. Pearl PL, Craiu D, et al. Subthalamic nucleus involvement in children: A neuroimaging pattern-recognition approach. Eur J Paediatr Neurol. 2014; 18(3):249-56. [PubMed: 24149100]

60. Wamelink MM, Roos B, Jansen EE, Mulder MF, Gibson KM, Jakobs C. 4-Hydroxybutyric aciduria associated with catheter usage: a diagnostic pitfall in the identification of SSADH deficiency. Mol Genet Metab. 2011; 102(2):216-7. [PubMed: 20965758]

61. Scriver CR, Pueschel S, Davies E. Hyper-beta-alaninemia associated with beta-aminoaciduria and gamma-aminobutyricaciduaia, somnolence and seizures. N Engl J Med. 1966; 274(12):635-43. [PubMed: 17926374]

62. Forni S, Pearl PL, Gibson KM, Yu Y, Sweetman L. Quantitation of gamma-hydroxybutyric acid in dried blood spots: feasibility assessment for newborn screening of succinic semialdehyde 
dehydrogenase (SSADH) deficiency. Mol Genet Metab. 2013; 109(3):255-59. [PubMed: 23742746]

63. Knerr I, Gibson KM, Murdoch G, Salomons GS, Jakobs C, Combs S, et al. Neuropathology in succinic semialdehyde dehydrogenase deficiency. Pediatr Neurol. 2010; 42(4):255-8. [PubMed: 20304328]

64. Gropman A. Vigabatrin and newer interventions in succinic semialdehyde dehydrogenase deficiency. Ann Neurol. 2003; 54(Suppl 6):S66-72. [PubMed: 12891656]

65. Casarano M, Alessandri MG, Salomons GS, Moretti E, Jakobs C, Gibson KM, et al. Efficacy of vigabatrin intervention in a mild phenotypic expression of succinic semialdehyde dehydrogenase deficiency. JIMD Rep. 2012; 2:119-23. [PubMed: 23430864]

66. Escalera GI, Ferrer I, Marina LC, Sala PR, Salomons GS, Jakobs C, et al. [Succinic semialdehyde dehydrogenase deficiency: decrease in 4-OH-butyric acid levels with low doses of vigabatrin]. An Pediatr (Barc). 2010; 72(2):128-32. [PubMed: 20018576]

67. Gibson KM, Hoffmann GF, Hodson AK, Bottiglieri T, Jakobs C. 4-Hydroxybutyric acid and the clinical phenotype of succinic semialdehyde dehydrogenase deficiency, an inborn error of GABA metabolism. Neuropediatrics. 1998; 29(1):14-22. [PubMed: 9553943]

68. Chambliss KL, Zhang YA, Rossier E, Vollmer B, Gibson KM. Enzymatic and immunologic identification of succinic semialdehyde dehydrogenase in rat and human neural and nonneural tissues. J Neurochem. 1995; 65(2):851-5. [PubMed: 7616245]

69. Grove J, Schechter PJ, Tell G, Koch-Weser J, Sjoerdsma A, Warter JM, et al. Increased gammaaminobutyric acid (GABA), homocarnosine and beta-alanine in cerebrospinal fluid of patients treated with gamma-vinyl GABA (4-amino-hex-5-enoic acid). Life Sci. 1981; 28(21):2431-9. [PubMed: 6789022]

70. Shinka T, Ohfu M, Hirose S, Kuhara T. Effect of valproic acid on the urinary metabolic profile of a patient with succinic semialdehyde dehydrogenase deficiency. J Chromatogr B Analyt Technol Biomed Life Sci. 2003; 792(1):99-106.

71. Vanadia E, Gibson KM, Pearl PL, Trapolino E, Mangano S, Vanadia F. Therapeutic efficacy of magnesium valproate in succinic semialdehyde dehydrogenase deficiency. JIMD Rep. 2013; 8:133-7. [PubMed: 23430529]

72. Pearl PL, Schreiber J, Theodore WH, McCarter R, Barrios ES, Yu J, et al. Taurine trial in succinic semialdehyde dehydrogenase deficiency and elevated CNS GABA. Neurology. 2014; 82(11):9404. [PubMed: 24523482]

73. Gibson KM, Gupta M, Pearl PL, Tuchman M, Vezina LG, Snead OC 3rd, et al. Significant behavioral disturbances in succinic semialdehyde dehydrogenase (SSADH) deficiency (gammahydroxybutyric aciduria). Biol Psych. 2003; 54(7):763-8.

74. Pearl PL, Taylor JL, Trzcinski S, Sokohl A, Dustin I, Reeves-Tyer P, et al. 11C-Flumazenil PET imaging in patients with SSADH deficiency (Abstract). J Inherit Metab Dis. 2007; 30(Suppl 1):43.

75. Kim YG, Lee S, Kwon OS, Park SY, Lee SJ, Park BJ, et al. Redox-switch modulation of human SSADH by dynamic catalytic loop. Embo J. 2009; 28(7):959-68. [PubMed: 19300440] 

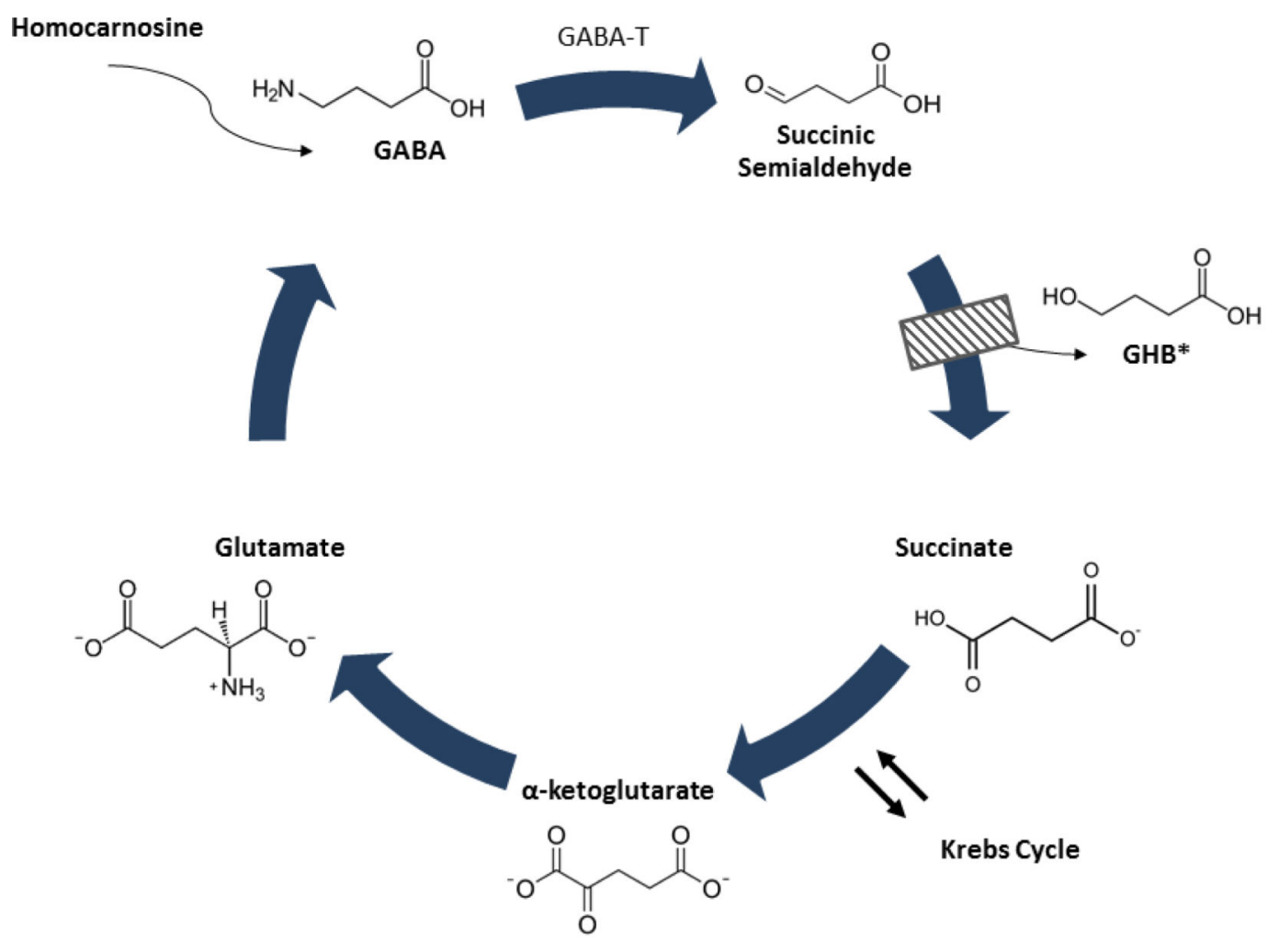

Figure 1.

GABA metabolic pathway 


\section{Table 1}

Clinical features in SSADH deficiency $(n=111)$

\begin{tabular}{lcc}
\hline Clinical features & Number & $(\boldsymbol{\%})$ \\
\hline Developmental delay & 83 & $(75)$ \\
Intellectual deficiency & 76 & $(69)$ \\
Hypotonia & 65 & $(59)$ \\
Behavioral problems & 68 & $(61)$ \\
Seizures & 39 & $(35)$ \\
Ataxia & 60 & $(54)$ \\
\hline
\end{tabular}

SSADH=Succinic semialdehyde dehydrogenase 
Table 2

Seizure types reported in patients with SSADH deficiency $(n=48)$

\begin{tabular}{lcc}
\hline Seizure types & Number & $(\%)$ \\
\hline Generalized tonic-clonic & 27 & $(56)$ \\
Absence & 23 & $(48)$ \\
Myoclonic & 15 & $(31)$ \\
Focal onset & 12 & $(25)$ \\
Unspecified & 9 & $(19)$ \\
\hline
\end{tabular}

SSADH=Succinic semialdehyde dehydrogenase 
Table 3

Electroencephalography findings in patients with SSADH deficiency $(n=58)$

\begin{tabular}{lcc}
\hline EEG findings & Number & $(\boldsymbol{\%})$ \\
\hline Normal electroencephalography & 24 & $(41)$ \\
Abnormal electroencephalography & 34 & $(59)$ \\
Background abnormal/slowing & 14 & $(24)$ \\
Spike discharges & 13 & $(22)$ \\
Electrographic status epilepticus during slow wave sleep & 1 & $(2)$ \\
Photosensitivity & 3 & $(5)$ \\
\hline
\end{tabular}

SSADH=Succinic semialdehyde dehydrogenase 